\title{
Predictive Power of Goal-striving Reasons for Self-reported and Actual Plastic Consumption
}

\author{
Christian Ehrlich, Samantha Miles \\ Oxford Brookes Business School, Oxford Brookes University, Oxford, UK
}

Email address:

cehrlich@brookes.ac.uk (C. Ehrlich)

\section{To cite this article:}

Christian Ehrlich, Samantha Miles. Predictive Power of Goal-striving Reasons for Self-reported and Actual Plastic Consumption. Humanities and Social Sciences. Vol. 9, No. 3, 2021, pp. 57-66. doi: 10.11648/j.hss.20210903.11

Received: February 15, 2021; Accepted: April 29, 2021; Published: May 8, 2021

\begin{abstract}
Background: Plastic waste is a major societal and environmental issue contributing to climate change as well as affecting the health of humans and animals across the globe. Tackling plastic pollution requires dramatic change from everyone because one of the key factors contributing to the amount of plastic waste is consumer behaviour. Objective: The aim of this research is to test the predictive power of the goal-striving reasons framework for plastic waste behaviour of UK households to analyse whether the reasons why people voluntarily engage in plastic reducing actions can predict plastic consumption of households. Method: The predictive power of the goal-striving reasons framework was tested by correlating the overall goalstriving reasons index and, each goal of the six goal-striving reasons individually, with i) a newly developed self-report measure of plastic consumption and; ii) with an objective measure of plastic waste. The objective measure required households to count their plastic waste for three consecutive weeks. The study is based on $N=66$ households in Oxfordshire, United Kingdom. Results: Findings suggest that the approach goal-striving reasons of pleasure, altruism and positive consequences are related to self-reported plastic waste whereas the two avoidance reasons of not wanting to feel bad about oneself or to avoid any negative consequences are related to objective plastic waste. Conclusion: The findings of this study highlight the relevance of the goal-striving reasons framework as an important concept for the prediction of plastic waste behaviour of individuals, and as a potential tool for facilitating change behaviour in household plastic waste consumption.
\end{abstract}

Keywords: Goal-Striving Reasons, Approach Reasons, Avoidance Reasons, Self-reported Plastic Waste, Objective Plastic Waste

\section{Introduction}

Plastic waste is a major societal and environmental issue. Plastics contribute to climate change through the emission of greenhouse gases [1-2]. Plastic waste adversely affects human health, not only through the ingestion of microbeads that have entered the food chain [3] but also through the impact of harmful chemical additives [4]. Toxic chemicals that leach from plastic waste are also known to be a source of soil degradation [5]. The UK government has identified the level of plastic pollution in the world's oceans as one of the most significant environmental challenges facing the world today [6]. It is a depressing thought that, according to the United Nations Environmental Programme, our oceans contain 500 times more micro-plastic particles than the number of stars in the sky, and that, by 2050 , it is forecast that there will be more plastic in the ocean than fish [7].
Moreover, the Covid-19 pandemic further contributed to excessive use of single use plastic items such as masks, gloves and wet wipes [8]. It is unsurprising therefore that the UNEP's Clean Seas Campaign has called for ambitious measures from businesses and countries to reduce the use of single-use plastic by 2022 [9]. This requires dramatic changes from everyone, especially as a comprehensive technological solution is unlikely in the very near future [2]. In this context it is important to note that significant amounts of plastic waste littering the environment is consumer (i.e. household) generated [10] and so any sustained solution has to include the reduction of plastic consumption on a consumer level [11].

Human behaviour towards waste consumption has been the subject of a plethora of research, albeit mainly investigating human intentions towards waste consumption/recycling of paper, cardboard, glass, cans and 
plastics [12-13]. To analyse the specific issue of plastic waste at a household level is particularly interesting given the immense media attention around plastic waste, alongside the fact that households currently experience no real negative consequences if they produce (excessive) plastic waste. In the absence of fines or taxes, any reduction in plastic waste, and the respective behaviour to achieve this, needs to be voluntary. Thus, tackling environmental pollution of plastic waste cannot be done without substantive, long-term transformations of the day-to-day behaviour of individuals [14].

With regard to the required long-term transformative changes, the informal rules that govern behaviour in societies, i.e. social norms (cf. [15]), have proven to be most influential in promulgating pro-environmental behaviour towards littering [16] and recycling [17]. However, whilst social norms are developing, driven by a growing number of NGO-led plastic initiatives and an increasing amount of media coverage on the environmental and societal impact of plastics, social norms alone are unlikely to be sufficient to stimulate the high levels of public participation required to tackle this issue. People need to make voluntary sacrifices. Hence further investigation is needed to understand the selfmotivations of human beings to voluntarily engage in plastic reduction.

In this context, the goal-striving reasons framework $(G S R F)$ [18-22], a recently developed concept which measures specific reasons why people engage in actions or goals, seems a promising concept to understand people's motivation to reduce plastic consumption. It seems promising because it permits the analysis of the reasons why people engage in their most important actions to reduce plastic consumption by differentiating between approach/avoidance reasons and within-person/person-environment reasons. The approach/avoidance dimension distinguishes between a reason for goal pursuit that is aimed at achieving a desired outcome (approach) and a reason that is aimed at avoiding undesirable outcomes (avoidance) [23]. Within-person reasons are reasons that are focused on consequences for the person itself (self-centred) whereas person-environment reasons are aimed at changing the external situation (selftranscendent reasons). This distinction is based on the classical categorisations of goal contents by Ford and Nichols [24]. Based on these two dimensions the GSRF identifies six ${ }^{1}$ specific goal-striving reasons that capture why people pursue their most important goals in life. The six reasons are i) when people strive for their goals out of pleasure (I enjoy the pursuit of my goal); ii) for altruistic reasons (the pursuit of my goal helps others); iii) for the positive consequences resulting from my goals (I will gain a lot); iv) self-esteem reasons (If I fail in this goal my self-esteem would suffer); v) out of necessity (I need to strive for this goals to avoid not

\footnotetext{
${ }^{1}$ Originally the GSRF was developed with four goal-striving reasons [18] but has also been extended to a six goal-striving reasons framework [19]. The two latest additions to the GSRF are positive and negative consequences. These are both within-person consequences, although they represent the more rational aspect of motivation whereby a goal is pursued as a means to an end.
}

being able to make a living), and vi) to avoid negative consequences (I would be worse off if I fail in this goal). ${ }^{2}$

Table 1. The extended Goal-striving reasons framework [16].

\begin{tabular}{|c|c|c|}
\hline & Approach & Avoidance \\
\hline $\begin{array}{l}\text { Within-person } \\
\text { (emotional) }\end{array}$ & Pleasure & Fear of self-esteem loss \\
\hline $\begin{array}{l}\text { Within-person } \\
\text { (rational) }\end{array}$ & $\begin{array}{l}\text { Positive } \\
\text { consequences }\end{array}$ & Negative consequences \\
\hline Person-environment & Altruism & Necessity \\
\hline
\end{tabular}

We argue that the two underlying dimensions and the six goal-striving reasons are highly pertinent in understanding people's motivation in relation to plastic consumption. The distinction between approach and avoidance reasons is important, for example, because research has shown that approach motivated behaviour is largely related to positive emotions, whereas avoidance driven behaviours are largely associated with negative emotions [25]. Thus, the inclusion of the approach/avoidance dimension allows further insight into the question of whether people engage more in plastic reducing behaviour when their behaviour is associated with positive emotions (enjoying to behave plastic conscious), or negative emotions (avoiding feeling guilty if one would not behave plastic conscious). In addition to that, the distinction between self-centred and self-transcendent reasons makes the GSRF a very pertinent model because reducing one's plastic consumption quite often requires behaviours that do not benefit oneself but the wider community, or may be motivated by peer or family pressures.

Given that the six goal-striving reasons are based on the two plastic relevant dimensions (approach/avoidance and within-person/person-environment) it is a natural conclusion that the six specific reasons are equally relevant for plastic consumption. This is because there can be a strong link between behaving environmentally friendly and experiencing positive emotions [26]. This suggests that positive emotions (pleasure) can be an important driver for people to reduce plastic consumption. At the same time, engaging in plastic reducing behaviour for the welfare of others has also been identified as a motivator for many to act in a more environmentally friendly manner (cf. [27-28]). Equally, the degree to which individuals feel bad about themselves or experience 'green-guilt' [29] is linked to self-esteem factors. The need to engage in environmentally friendly behaviour to be able to make a living (i.e. out of necessity) ${ }^{3}$, is a rational reason why people engage in pro-environmentally friendly behaviour as buying in bulk to deliver cost savings reduces like-for-like plastic packaging. This indicates that the GSRF reasons are relevant for plastic reducing behaviour. Finally, operational conditioning [30] suggests that our behaviour towards plastic consumption is also shaped by the positive and negative consequences we experience when engaging in

\footnotetext{
${ }^{2}$ Negative consequences differ from necessity insofar as negative consequences capture the less severe detrimental consequences whereas necessity captures the essential consequence of not being able to make a living..

${ }^{3}$ Admittedly this will, in many cases, quite often not be the case as shopping plastic-free is still associated with paying more for products..
} 
any plastic-reducing behaviour. Based on this evidence we argue that the GSRF is a promising concept which can give further insights into the motivational factors of individuals and their plastic consumption.

Testing the suitability of the GSRF for the prediction of plastic waste behaviour requires the existence of measures for plastic consumption. Unfortunately, such specific plastic waste measures do not exist. Most available measures are on the wider subject of general environmental behaviour including a variety of environmentally friendly behaviours rendering them unsuitable for a specific plastic waste measure. Consequently, the current study developed a specific self-report plastic measure as well as a specific objective (actual) plastic measure consisting of a record of a household's plastic waste over three weeks. The use of an objective and subjective plastic waste measure allows to test whether self-reported plastic waste is predicted by different goal-striving reasons compared to objective plastic waste. This is loosely related to the value-action gap [31-32] whereby people's self-reported behaviours or intentions diverge from their actual behaviour. This value-action-gap might be particularly important within the issue of plastic consumption where social desirability, i.e. the desire to overstate one's positive behaviour, can be assumed to be likely. Hence, it is important to analyse the predictive power of people's reasons for engaging in plastic waste reducing behaviour in relation to their self-reported waste as well as their objective (actual) plastic waste.

Against this backdrop, the aim of this research is to test the predictive power of the goal-striving reasons framework for plastic waste behaviour of UK households. This includes the analysis of the relationships between specific goal-striving reasons and self-reported plastic waste as well as actual plastic consumption.

\subsection{Plastic Consumption in UK Households}

The official recycling rate of plastic packaging waste in the UK is $46.2 \%$ [33]. Whilst this exceeds the current EU target of $22.5 \%$, it is considerably lower than $79 \%$ for paper/cardboard and $67.6 \%$ for glass [33], partly because plastic waste, such as cling film and wet wipes cannot be recycled into new products. In addition black plastic cannot be detected by the optical sorting equipment at recycling facilities and so is currently non-recyclable. Many local authorities in the UK provide guidance for households on which types of plastics can, and cannot, be recycled, leading to a considerable amount of plastics, such as pet food pouches, pill blister packs and crisp packets going straight into landfill or subject to incineration, releasing toxic pollutants into the atmosphere. In addition, plastic recycling rates are likely to be lower than official figures suggest, because the UK lacks sufficient infrastructure to cope with increasing waste levels and consequently exports around $27 \%$ of plastic waste $(611,000$ tonnes $)$ as a 'cheap' solution. This exceeds the 478,000 tonnes of plastic waste that Defra reported was recycled from households in 2018 [34] and amounts to $2.2 \%$ of waste from UK households

\section{(22 million tonnes).}

Traditional approaches to reduce waste, or to encourage recycling, have been punitive, with a focus on 'pay as you throw' gate fees or 'pay as you use' levies, although these schemes mostly apply to a B2B level. Some schemes are aimed at consumers. For example in the UK the 5 p charge on single-use plastic carrier bags has resulted in the reduction of their use by over $80 \%$ [35]. Overall, there is a critical lack of pricing of waste at the household level in the UK. Households pay no direct charge based on the amount of waste because local authorities are prohibited from charging specifically for their waste collection service [36]. Therefore, waste sorting efforts by households depends on the goodwill of individuals, as does motivations for pro-environmental behaviour towards reducing plastic consumption.

\subsection{The Relevance of Motivational Theories to Predict Plastic Reducing Behaviour}

Among the plethora of motivational theories to apply to the issue of plastic consumption this study draws on motivational theories that focus on the 'why of goal-pursuit'. This is because research has shown that the reasons why people strive for their goals or engage in certain actions are important factors explaining how people feel during goal pursuit [37-39]. It therefore seems obvious to conclude that differences in the reasons why people engage in any plastic reducing behaviour should make a difference to their plastic consumption. Hence, theories focussing on the "why of goalpursuit' can be assumed to be applicable in the context of plastic consumption. The most predominant model that focuses on the 'why' of goal pursuit is Sheldon and Elliot's self-concordance theory [40]. Self-concordance theory applies the thinking of self-determination theory to people's idiosyncratic goals [41]. Thus, self-concordance theory measures the degree to which individuals pursue their goals for autonomous or controlled reasons. Autonomous reasons involve internalised forms of motivation which are integrated with a person's self [40]. Such goals emanate from selfchoices, driven by intrinsic motivation or self- identified motivation (personal convictions). Controlled goal motivations emanate from external forces to which the individual does not fully assent to [37]. This may be because the situation demands a particular action or because failure to pursue a particular goal would induce feelings of guilt, anxiety or shame.

Self-concordance theory suggests that when people select goals that reflect their personal interest, natural tendencies, or core values, their effort to achieve these goals will be more effective and sustained [40], compared to goals which are motivated by external pressures, as these are driven by introjected guilt or external compulsion [42]. Hence an individual desire to 'save the planet' based on personal principles should materialise into more sustained proenvironmental behaviour compared to obliging proenvironmental behaviour due to the requests from authorities. Based on these arguments it can be concluded that selfconcordance theory provides a useful lens to explore plastic 
waste behaviour. Despite this, there are hardly any studies that have employed self-concordance theory to predict environmentally friendly behaviour [43]. To our knowledge only Unsworth and McNeill [43] provided empirical evidence, across three studies, for the hypothesis that people's self-concordance is strongly related to environmental-friendly behaviour.

Despite this initial evidence for the applicability of selfconcordance theory to the issue of plastic consumption, we argue that self-concordance theory also has its limitations within this context for the following reasons. Firstly, based on the overarching recommendation to provide individuals with an autonomy supportive environment to allow them to develop self-concordant goals, we argue that, in the context of an environmental crisis such as plastic pollution, a more directive approach to encourage people to reduce their plastic consumption is needed. Secondly, self-concordance theory underestimates the (reinforcing) influence that other people have on people's motivation for their goal, as it focuses on autonomous goal strivings (i.e. on task-inherent factors) (see [44]). The analysis of the reduction of plastic waste at the household level must therefore incorporate some consideration of the influence of others (e.g. family members) to reduce consumption. In this context Ehrlich argued that the goal-striving reasons framework is more sensitive to the influence that others can have on the reasons why people pursue their goals [19]. This is because the goalstriving reasons framework distinguishes between approach and avoidance reasons, which, as a result, considers the desire to strive for a particular goal because of the anticipated reactions from others. Self-concordance theory, because of its focus on the task-inherent motivational factors, excludes this factor. Thirdly, self-concordance does not explicitly capture the idea of 'altruism' [18]. For example, the self-concordant reason 'I strive for a goal because it is important to me' could be motivated by a desire to impress others (importance of good standing and respect) rather than an altruistic desire to improve society and the environment for others. This is, however, not an unselfish way of engaging in environmentally friendly behaviour. On the contrary, the goal-striving reasons framework explicitly asks for the altruistic reasons - to what extent are you engaging in plastic actions to help others or to make the world a better place? In sum, the arguments provided above suggest that the recently developed goal-striving reasons framework seems to be more applicable in the context of plastic waste reduction than selfconcordance theory.

\section{Methods}

\subsection{Participants}

Participants of this study were households with at least one child attending one of two primary schools in Oxfordshire (United Kingdom). Both schools were reasonably similar with regards to their Office for Standards in Education (Ofsted) report (good and outstanding) and their demographic profile, apart from their size. One school was considerably larger (400 households) compared to the second school ( 80 households).

The research comprised three parts: i) completion of an online questionnaire on self-reported plastic waste behaviour by the main shopper of the household; ii) completion of an objective (actual) plastic waste measure over a three week period, and; iii) completion of an online questionnaire about the reasons why people engage in their two most important plastic waste reducing actions. The sample differed over the three stages: 139 households completed the online questionnaire; 90 of these households completed the objective plastic waste measure for the period of three weeks, of whom 66 also completed the online questionnaire about two of their most important plastic actions. As can be seen from table 2, the age and gender distribution as well as the general attitude towards plastic waste was similar between the groups. The overall household income as well as the level of formal education was relatively high.

Table 2. Participants'demographics and attitudes toward plastic pollution.

\begin{tabular}{|c|c|c|}
\hline & $\begin{array}{l}\text { Online questionnaire } \\
N=139\end{array}$ & $\begin{array}{l}\text { Online questionnaire with } 2 \text { plastic actions \& } \\
\text { plastic waste sheet } N=66\end{array}$ \\
\hline & $\mathrm{M}(\mathrm{SD})$ & $\mathrm{M}(\mathrm{SD})$ \\
\hline Age of main shopper & $42.39(5.68)$ & $43.03(5.32)$ \\
\hline \multirow[t]{2}{*}{ Gender of main shopper } & $87 \%$ female/ & $83 \%$ female \\
\hline & $13 \%$ male & $17 \%$ male \\
\hline How many people in household & $2.00(.40)$ & $2.06(.42)$ \\
\hline How many children under 18 in household & $1.98(.76)$ & $2.06(.76)$ \\
\hline Gross annual & Under $£ 10.000: 0.7 \%$ & $0 \%$ \\
\hline \multirow[t]{3}{*}{ household income } & $£ 10.001-20.000: 5.8 \%$ & $6.1 \%$ \\
\hline & $£ 20.001-30.000: 2.9 \%$ & $1.5 \%$ \\
\hline & Over $£ 30.000: 85.6 \%$ & $92.4 \%$ \\
\hline \multirow[t]{5}{*}{ Formal education } & No formal education $0.7 \%$ & $0 \%$ \\
\hline & CSE/O-level/GCSE $0.7 \%$ & $1.5 \%$ \\
\hline & A-level, FE-college $7.2 \%$ & $6.1 \%$ \\
\hline & Undergraduate $30.2 \%$ & $31.8 \%$ \\
\hline & Postgraduate $57.6 \%$ & $60.6 \%$ \\
\hline There is far too much plastic waste & $4.76(.78)$ & $4.78(.73)$ \\
\hline Plastic waste is a big problem for our planet & $4.72(.83)$ & $4.78(.75)$ \\
\hline Plastic waste is causing severe damage to animals & $4.66(.81)$ & $4.74(.70)$ \\
\hline
\end{tabular}




\begin{tabular}{lll}
\hline & $\begin{array}{l}\text { Online questionnaire } \\
\boldsymbol{N}=\mathbf{1 3 9}\end{array}$ & $\begin{array}{l}\text { Online questionnaire with 2 plastic actions \& } \\
\text { plastic waste sheet } \boldsymbol{N}=\mathbf{6 6}\end{array}$ \\
\hline Plastic waste is causing severe damage to the oceans & $4.74(.77)$ & $4.80(.66)$ \\
Plastic pollution is damaging people's health & $4.18(.91)$ & $4.15(.80)$ \\
Plastic pollution is causing severe damage to air quality & $3.87(1.01)$ & $3.71(.95)$ \\
\hline
\end{tabular}

Note: Plastic Waste attitude was measured on a five point Likert scale ranging from $1=$ strongly disagree to $5=$ strongly agree (completed by main shopper).

\subsection{Procedure}

Following approval of the project by the University Research Ethics Committee, participants were recruited through school communication channels. The project was introduced to the children during school-wide assembly. A letter was subsequently sent to the parents for the attention of the main shopper of the household, directing them to complete the online questionnaire prior to the start of the recording of the physical plastic waste produced by the household the following week. A plastic waste sheet was supplied to each participating household. This detailed common items of plastic waste and required participants to keep a separate, itemised, record of physical plastic waste for each of the three weeks.

\subsection{Measures}

\subsubsection{Self-reported Plastic Waste}

As no questionnaire on household plastic waste existed a new measure for self-reported plastic waste was developed. To do so, a pool of 35 questions was created which spread across five categories as follows: Shopping behaviour (13 items), for example the selection of soap rather than shower gel in a plastic bottle; Reuse of plastic items (7 items), such as taking a refillable cup when purchasing take away beverages; Active behaviour to tackle plastic waste (3 items), such as picking up plastic litter; Avoidance of plastic generating behaviour ( 8 items), such as avoiding buying items in black plastic trays, and; Educating others how to reduce plastic consumption (4 items).

The items were subjected to a principal component analysis (varimax rotated) using all participants who completed the questionnaire $(\mathrm{N}=139)$. Initially, the number of factors to extract was set to five in line with the five anticipated categories of plastic behaviour. Items were eliminated if they exhibited factor loadings of less than .68 (the criteria of . 70 was slightly lowered as it would have led to a large number of items being eliminated) and crossloadings of less .20 on any non-target factor. This led to a final factor solution of three factors representing "general plastic avoidance behaviour (4 items)", plastic behaviour related to personal hygiene ( 3 items)" and "Educating others (2 items)". The final factor solution is presented in table 3 . Respective Eigenvalues for the 3 factors are hereby (Factor $1=36 \%$; Factor $2=16 \%$, Factor $3=16 \%$ ).

Table 3. Principal component analysis on self-report plastic measure.

\begin{tabular}{|c|c|c|c|}
\hline Do you..... & Factor 1 & Factor 2 & Factor 3 \\
\hline avoid buying food in supermarket that is wrapped in plastic/cling film & .69 & & \\
\hline prefer to eat in a restaurant/cafe that does serve "proper" cutlery instead of single use plastic & .68 & & \\
\hline avoid using single use plastic cups & .85 & & \\
\hline avoid using single use plastic cutlery & .90 & & \\
\hline use shampoo bars instead of shampoo in plastic bottles & & .82 & \\
\hline use soap bars instead of shower gel in plastic bottles & & .81 & \\
\hline buy washing up liquid/detergent in plastic free shops & & .71 & \\
\hline encourage family/friends to pick up plastic litter & & & .90 \\
\hline pick up plastic rubbish on the street/beach & & & .87 \\
\hline
\end{tabular}

Note. $\mathrm{N}=139$. Loadings greater than .50 are presented.

\subsubsection{Goal-striving Reasons}

The GSRF has been used to capture the reasons why households (represented through the main shopper of the household) engage in plastic waste reduction. To this end, the version published in 2018 [19] was adapted to the topic of plastic waste behaviour. Participants were asked within the questionnaire to identify two important actions taken to tackle plastic waste and then asked to rate "why they engaged in this activity". Examples of items are: I engage in this activity because: "...it helps others" (altruism); "I need the money" (necessity); "I am having fun" (pleasure); "if I didn't do it my reputation amongst others would drop" (loss of selfesteem). Participants were required to answer on a seven point Likert scale ranging from $1=$ not true at all to $7=$ very true. The applications of items to the issue of plastic behaviour revealed similar results with regard to internal reliability of the scales, with the exception of the item "I gain a lot from this activity" contributed to low internal reliability of the scale and therefore has been eliminated (see Table 4).

The goal-striving reasons framework permits the calculation of an overall goal-striving reasons index (GSRI) which has been used in previous studies as an overall measure of people's goal-striving reasons. This index is created by adding up the average scores for each of the three approach reasons over both of the plastic waste actions. From this score the average scores for all three avoidance reasons is then subtracted resulting in a single goal-striving reasons index. 


\subsubsection{External Social Pressures}

External social pressures have been measured by using five items. Each of the items was precluded by the phrase: "I engage in actions to reduce plastic waste because...". All items represent some form of externalised pressure. The five items were: "I have been told to do it", "It pleases others", "It is generally seen as a good thing to do", "I would feel guilty or ashamed if I didn't do it" and "This is what you do as a good citizen". Participants were asked to answer on a five point Likert scale ranging from $1=$ not at all to $5=$ very much. Internal reliability of these measures were sufficient (see Table 4).

\subsubsection{The Objective Plastic Waste Measure}

The objective measure for plastic waste behaviour has been created by conducting a list of common household plastic items. It was felt that the best indicator for people's plastic consumption is the amount of items across a wide range of plastic items. This reflects the varied demographic characteristics of households, for example that households with a baby might use proportionally more wet wipes but less plastic drink bottles, compared to households with older children. A waste measurement sheet was produced which identified 30 categories of plastic items whereby different sizes were not considered. These included drink and food related items, for example drinks bottles, yoghurt pots, straws, ready meal trays, pet food pouches and so forth. It is acknowledged that the objective waste measure will not capture $100 \%$ of plastic waste as some waste may be disposed of in public litter bins, and some plastic waste that is not capable of being recycled may have been included in general rubbish for some households and so therefore not considered. Households were asked to record all plastic items over three consecutive weeks (recyclable and nonrecyclable).

\section{Results}

\subsection{Descriptive Statistics}

The descriptive statistics for the respondents who completed the self-report measure for plastic waste, the objective plastic waste measure sheet as well as goal-striving reasons over two plastic actions are shown in table 4 .

Table 4. Descriptive statistics of main study variables.

\begin{tabular}{|c|c|c|c|c|c|c|c|c|c|c|c|c|c|c|c|c|}
\hline & $\mathbf{M}$ & SD & $<$ & 1 & 2 & 3 & 4 & 5 & 6 & 7 & 8 & 9 & 10 & 11 & 12 & 13 \\
\hline 1) GSRI & 10.48 & 2.52 & .92 & & $.36^{* *}$ & $.41^{* *}$ & $.41^{* *}$ & $-.40^{* *}$ & $-.32^{* *}$ & $-.55^{* *}$ & -.02 & $.27^{*}$ & $.28^{*}$ & .15 & .21 & .06 \\
\hline 2) Pleasure & 3.64 & 1.40 & .91 & & & $.28^{*}$ & $.37^{* *}$ & $.38^{* *}$ & $.32^{* *}$ & .22 & .19 & $.40^{* *}$ & $.41^{* *}$ & .20 & $.33^{* *}$ & -.17 \\
\hline 3) Altruism & 5.99 & 0.93 & .83 & & & & $.44^{* *}$ & $.28^{*}$ & .03 & .13 & .05 & $.31^{*}$ & $.37^{* *}$ & .13 & .24 & -.23 \\
\hline 4) Pos. consequences & 6.37 & 0.64 & .71 & & & & & $.31^{* *}$ & -.06 & .12 & .13 & $.41^{* *}$ & $.45^{* *}$ & $.29^{*}$ & .22 & -.14 \\
\hline 5) Self-esteem & 2.33 & 1.39 & .93 & & & & & & .21 & $.47^{* *}$ & $.26^{*}$ & .18 & .23 & .13 & .05 & $-.30^{*}$ \\
\hline 6) Necessity & 1.32 & 0.61 & .81 & & & & & & & $.32^{* *}$ & .01 & -.02 & .05 & -.17 & .08 & .04 \\
\hline 7) Neg. consequences & 1.86 & 1.07 & .88 & & & & & & & & .11 & .18 & .14 & .12 & .15 & $-.28^{*}$ \\
\hline 9) Subjective Plastic Waste & 2.93 & 0.76 & .81 & & & & & & & & & & $.75^{* *}$ & $.80^{* *}$ & $.69^{* *}$ & $-.31^{* *}$ \\
\hline 10) Plastic Avoidance & 3.77 & 0.83 & .83 & & & & & & & & & & & $.50^{* *}$ & $.28^{*}$ & $-.36^{* *}$ \\
\hline 11) Plastic Personal Hygiene & 2.18 & 1.17 & .76 & & & & & & & & & & & & $.24^{*}$ & $-.38^{* *}$ \\
\hline 12) Plastic Education & 2.85 & 1.05 & .80 & & & & & & & & & & & & & .02 \\
\hline 13) Objective Plastic Waste & 0.00 & 5.93 & $\mathrm{n} / \mathrm{a}$ & & & & & & & & & & & & & \\
\hline
\end{tabular}

Note. $N=66 . * p<.05$. $* * p<.01$.

The results for the goal-striving reasons indicate that the sample reported to have stronger approach reasons than avoidance reasons, resulting in a high goal-striving reasons index. The findings for the self-reported plastic waste behaviour also reveal that the sample reported plastic avoidance behaviour the most frequently, followed by plastic education, whereas behaviour relating to personal hygiene was reported the least. The sample also reported a moderate sense of social pressure to reduce their plastic waste.

The descriptive statistics for people's objective plastic waste consumption reveal, in the first instance, a large diversity in the use of the plastic items. For example, for the three week period observed, the amount of drink bottles generated within a household ranged from 0 to $15^{4}$, whereas the amount of wet wipes ranged from 0 to 550 . Some of the means are also quite low, which is mostly due to the fact that in some cases a substantial amount of households did not

\footnotetext{
${ }^{4}$ In this context it should be noted that the school children could dispose of drink bottles in school. These did not count towards the household plastic consumption at home.
}

report to have consumed any of the products in question. ${ }^{5}$ Furthermore, there were no significant inter-correlations between each of the item-categories.

An overall score for household plastic consumption was created by transforming the amount of items in each category in a z-score. The z-scores for each of the categories of plastic items have then been added up over all plastic items. As a consequence the overall mean of the objective plastic waste measure is zero (see Table 4). Table 5 shows the average plastic consumption of all participants who completed the objective waste measure sheet for the entirety of the three weeks.

\subsection{Correlation Analysis}

Analyses have been conducted to test if, and how, these various measures are related to each other. Table 4 shows that GSRI correlates with subjective reported plastic waste but not with objective waste. At the same time, subjective plastic waste correlates negatively with objective plastic waste.

\footnotetext{
${ }^{5}$ As these correlations are not significant the results are not presented.
} 
External pressure was not significantly correlated with subjective or objective plastic waste.

Given these findings it seemed important to test for common method variance, as GSRI and self-reported waste were measured within the same questionnaire. However, performing the Harman's one-factor test indicated that only $34 \%$ of variance could be explained through a single factor which suggests that common method variance is unlikely to have occurred.

Looking into the relationships between some of the specific goal-striving reasons and self-reported and objective plastic waste, Table 3 shows that only the three approaching goal-striving reasons (pleasure, altruism and positive consequence) are associated with higher levels of selfreported plastic waste reduction whereas the avoidance goalstriving reasons are not significantly correlated with selfreported plastic waste. When analysing the correlation between the six goal-striving reasons and objective waste the two avoidance reasons of self-esteem and negative consequences are the only goal-striving reasons significantly related with objective waste.

\section{Discussion}

Overall the findings of this study suggest that goal-striving reasons are important predictors for people's plastic consumption. This however, needs to be qualified, as the overall GSRI contributed only marginally to our understanding of plastic consumption, due to the fact that it correlated with self-reported plastic waste but not with objective plastic waste. The analyses of individual goal-striving reasons level produced more insightful results. Here, the findings suggest that all three approach goal-striving reasons are important predictors of selfreported plastic waste whereas two avoidance components (self-esteem and negative consequences) are important predictors of objective plastic waste.

The findings therefore suggest that people's self-reported plastic waste consumption is very much associated with the degree to which people engage in plastic waste reduction for positive reasons. If people feel that the actions they take are because they enjoy doing it, because they feel it makes the world a better place or it has positive consequences for them, then they are likely to think - and report- to have lower levels of plastic consumption. This suggests that approach reasons might be more a reflection of how people would like to see themselves behaving towards plastic waste. Hence, the issue of social desirability, i.e. the tendency to give socially desirable responses [45] might come into play here.

On the contrary, the findings on objective plastic waste suggest that the actual plastic consumption of people is very much associated with avoidance reasons. Whether people actually produce less plastic waste is more associated with feeling bad about oneself (self-esteem) if one would not engage in plastic reducing behaviours. Equally, the fact that one would be worse off (negative consequences) if one would not engage in certain plastic reducing behaviours is also significantly related to people's actual plastic waste.
The findings regarding self-esteem indicate that people need to feel very strongly about plastic waste to motivate actions to reduce their plastic waste on the basis that they would feel bad about themselves if they did not do so. Thus, the values or norm to produce as little as possible plastic waste need to be internalised, i.e. these norms need to be personally endorsed values [37]. This is further substantiated by the fact that external social pressure was not a significant predictor of objective plastic waste in this study; thus external pressure from others seems less relevant in this context. One reason for this might be plastic-specific as it is still very much acceptable in our society to buy plastic items simply because most of the time people are given limited alternative choice when shopping. This limits the extent of social pressure that others could exert. Furthermore, it is also important to note that, in this study, the focus was on household plastic waste which is produced at home and not visible to others.

The amount of actual, objective plastic waste is also significantly correlated with negative consequences if one does not engage in plastic reducing behaviour. This supports the importance of financial rewards to encourage plastic reducing behaviour. It is also in line with already existing plastic reducing schemes such as the 5 p charge for plastic bags which had a positive impact on people's plastic consumption. It also concurs with the notion that the plastic waste is at least as much an avoidance issue (how to avoid plastic waste; how to avoid ruining our planet) than it is an approach issue (wanting to save the planet).

In addition to the findings on the relationship between goal-striving reasons and plastic waste behaviour, the study at hand also developed new measures for subjective and objective plastic waste consumption which we see as an additional contribution to the field of research on plastic waste consumption. With regard to the self-reported plastic waste measure this study suggests that one way of capturing self-reported plastic waste is through three distinct factors. These are 1) how much people report to avoid buying plastic items (Plastic Avoidance), how much they avoid the use of plastic when it comes to personal hygiene (Plastic Hygiene) and how much they engage in educating others to consume less plastics (Plastic Education).

Table 5. Descriptive statistics of objective plastic waste.

\begin{tabular}{lllll}
\hline & Min & Max & $\boldsymbol{M}$ & $\boldsymbol{S D}$ \\
\hline Drink bottles & 0.00 & 31.00 & 6.75 & 7.41 \\
Milk bottles & 0.00 & 18.00 & 7.16 & 4.88 \\
Frappuccino & 0.00 & 26.00 & 2.00 & 5.25 \\
Plastic cups & 0.00 & 15.00 & 4.01 & 3.28 \\
Plastic straws & 0.00 & 16.00 & 1.04 & 2.68 \\
Drink pouches, fruit shoots & 0.00 & 38.00 & 2.60 & 7.34 \\
Fruit, vegetable, meat trays & 0.00 & 105.00 & 26.28 & 18.86 \\
Sandwich wrapper & 0.00 & 6.00 & 0.65 & 1.50 \\
Plastic food bags & 1.00 & 218.00 & 44.65 & 36.64 \\
Convenience food plastics & 0.00 & 201.00 & 9.66 & 25.38 \\
Plastic cutlery & 0.00 & 3.00 & 0.24 & 0.70 \\
Crips/popcorn packet & 0.00 & 49.00 & 14.78 & 10.71 \\
Cling film & 0.00 & 52.00 & 9.77 & 12.34 \\
Wet wipes & 0.00 & 550.00 & 44.34 & 104.61 \\
\hline
\end{tabular}

Note. $\mathrm{N}=66$. 
With regard to the objective plastic waste measure the findings suggest that an objective plastic waste measure is more suitable when it measures the consumption of a large amount of plastic items rather than picking only a few items as an indicator of people's plastic waste consumption. This is mostly because of the fact that the various categories of plastic items within this study were hardly correlated with each other. Hence, picking only a few indicative plastic items as a meaningful representative of a households' overall use of plastic seems inappropriate. At the same time, the findings of this study suggest that 14 categories of plastic items are a sufficient number of categories for meaningful analysis, keeping in mind that having a categorisation of more than 30 items might be too cumbersome to record for participants. Equally, the employed plastic waste measure only captured the amount of items in a particular category not the actual size of it. This meant a plastic water bottle of $250 \mathrm{ml}$ contributed to the overall plastic waste of a household in the same way as a 2.5 litre plastic bottle. This is very crude but it seems to be a feasible way of capturing objective plastic waste as this method permits the distinction between plastic conscious individuals with zero or nearly zero consumption of a particular plastic item and those who have a high consumption of this item. Furthermore, it can also be assumed that plastic conscious individuals prefer to "bulk buy" where possible, resulting in lower consumption of plastic packaging and fewer plastic items.

\subsection{Limitations}

The findings of this study have to be treated with care. This is because the findings are based on a rather small sample size which is due to the fact that capturing one's household plastic waste for three consecutive weeks was a substantial commitment for households. However, because of the small sample size the analyses were limited to correlation analyses. The sample as such is also not representative for the whole of the UK. Hence, with regards to external validity, the findings cannot be generalised to less well-off, or less educated, households where, as some research related research suggests plastic waste behaviour might be different [46-47] .

Methodologically, it is also important to note that a selfreported plastic waste measure, as well as the goal-striving reasons, have been completed by the same person (main shopper of household) whereas the objective waste has been recorded by the household. Essentially, this could be an alternative explanation as to why the overall goal-striving reasons index correlated with the subjective plastic waste measure but not with the objective waste measure.

\subsection{Implications}

Despite these limitations the findings have important implications. Firstly, the results suggest that the motivational predictors for self-reported plastic waste are likely to differ from the motivational predictors for people's objective plastic waste. This indicates that studies into the relationship between people's motivation for reducing their plastic consumption and their actual plastic consumption might benefit from including measures of objective plastic consumption rather than solely relying on self-reported plastic waste measures.

The results also highlight the importance for plastic waste initiatives to focus on that sense of unease (loss of selfesteem) within individuals for not engaging in plasticreducing behaviours as an effective way to reduce actual plastic waste. Here the process of integrated internalisation, a process whereby people internalise external societal demands and integrate them into their own value system [37], can be assumed to be an important consideration that should underpin future plastic campaigns. People will only feel uneasy about not engaging in plastic reducing behaviour if they have internalised the need to produce less plastic waste. Hence, future campaigns should focus more on the internalisation process rather than on building up external pressures as such. Very importantly in this context is hereby the notion that this internalisation process should focus on internalising an avoidance driven motivation (reducing one's plastic consumption to avoid feeling bad about oneself) and not an approach motivation (reducing one's plastic consumption feels good). Campaigns can hereby draw on existing research that identified relevant contextual factors that allow for the integration of external societal requests. For example, it has been demonstrated that the integrative form of internalisation is facilitated if one provides a meaningful rationale for the social demand, if one acknowledges the individual's feelings, as well as if one offers choice to the individual on how to pursue plastic reducing actions [48].

The reason to focus more strongly on internalisation rather than on external, societal pressures in relation to the specific issue of plastic waste is further substantiated by the fact that currently consumers, particularly in supermarkets, have a restricted choice in relation to buying plastic-free. As a consequence, it is still "acceptable" or the norm to buy things wrapped in plastic. Also, plastic consumption within households is a rather private matter and the extent to which households produce plastic waste is typically not easy to observe for others. Both of these factors can explain why external pressures might be less effective than real negative consequences for failing to engage in plastic reducing behaviour.

Furthermore, the findings of this study also reiterate the importance of negative consequences for not engaging in plastic reducing actions. This is in line with the findings around the introduction of the $5 \mathrm{p}$ charge for plastic bags and its successful reduction in plastic consumption. More importantly, the results of this study also show that negative consequences are a significant predictor of objective plastic waste consumption whereas external pressures are not.

\subsection{Future Research}

The findings of this study also stipulate future research. Mostly, studies with larger sample sizes are needed to test if these preliminary findings can be replicated, especially given the fact that both measures for plastic waste were created for 
this study. It would also be important to see whether conducting this study with single-occupancy household's yields even stronger relationships between people's goalstriving reasons and plastic waste consumption. Finally, this study only required participants to state two plastic actions as an indicator of their goal-striving reasons. This indicator might gain further predictive power if based on a larger number of plastic actions, for example four actions.

\subsection{Conclusion}

To conclude, this study presents preliminary findings about the relevance of people's goal-striving reasons for plastic waste consumption. The findings indicate that approach goalstriving reasons are important predictors for self-reported plastic waste whereas the two avoidance reasons of selfesteem and negative consequences are important predictors for people's objective plastic consumption. The GSRF is thereby a potential tool for facilitating change behaviour in household plastic waste consumption.

\section{Conflict of Interest}

The authors declare that they are in no conflict of interest.

\section{References}

[1] Royer S-J, Ferrón S, Wilson S. T \& Karl D. M. (2018) Production of methane and ethylene from plastic in the environment. PLoS ONE 13 (8).

[2] Heidbreder, L. M., Bablok, I., Drews, S. \& Menzel, C. (2019). Tackling the plastic problem: A review on perceptions, behaviors, and interventions. Science of the Total Environment, 668, 1077-1093

[3] Seltenrich, N. (2015). New link in the food chain? Marine plastic pollution and seafood safety. Environmental Health Perspective, 123 (2), 34-41.

[4] Hodson, M.E., Duffus-Hodson, C.A., Clark, A., PrendergastMiller, M.T. \& Thorpe, K.L., (2017). Plastic bag derivedmicroplastics as a vector formetal exposure in terrestrial invertebrates. Environmental Science and Technology 51 (8), $4714-4721$

[5] Khan, F., Ahmed, W. \& Najmi, A. (2019). Understanding consumers' behavior intentions towards dealing with the plastic waste: Perspective of a developing country. Resources, Conservation \& Recycling 142, 49-58

[6] de la Mare, T. (2018). Government promises $£ 61 \mathrm{~m}$ to tackle scourge of ocean plastic pollution with Commonwealth nations. The Independent, 15 April. Available at: https://www.independent.co.uk/environment/theresa-maycommonwealth-plastic-climate-change-ocean-pollution-davidattenborough-blue-planet-a8305721.html (accessed 29 September 2018).

[7] Jennings, F. J.,Allen, M. W., \& Phuong, T., L., V. (2020). More Plastic than Fish: Partisan Responses to an Advocacy Video Opposing Single-Use Plastics, Environmental Communication. Online first.
[8] Silva,A. L. P, Prata, J. C.,Walker T. R., Duarte, A.C., Ouyang, W., Barcelò, D. \& Rocha-Santos, T. (2020). Increased plastic pollution due to COVID-19 pandemic: Challenges and recommendations, Chemical Engineering Journal, Volume 405, Online first.

[9] UN (2017). 'Turn the Tide on Plastic' Urges UN, as Microplastics in the Seas Now Outnumber Stars in Our Galaxy. 23 February. Available at: https://news.un.org/en/story/2017/02/552052-turn-tide-plasticurges-un-microplastics-seas-now-outnumber-stars-ourgalaxy\#.WTE4nhOGPsE (accessed 18 February 2020).

[10] Carpenter, E. \& Wolverton, S. (2017). Plastic litter in streams: the behavioral archaeology of a pervasive environmental problem. Applied Geography 84, 93-101.

[11] Löhr, A., Savelli, H., Beunen, R., Kalz, M., Ragas, A., \& Van Belleghem, F. (2017). Solutions for global marine litter pollution. Current Opinion in Environmental Sustainability, 28, 90-99.

[12] Barr, S. (2007). Factors influencing environmental attitudes and behaviors: A UK case study of household waste management. Environment and Behavior, 39, 435-473.

[13] Chan, K. (1998). Mass communication and pro-environmental behaviour: waste recycling in Hong Kong, Journal of Environmental Management, 52, 317-325.

[14] Yamin, P., Fei, M., Lahlou, S. \& Levy, S. (2019). Using Social Norms to Change Behavior and Increase Sustainability in the Real World: a Systematic Review of the Literature. Sustainability, 11, 5847.

[15] Cialdini, R. B., \& Trost, M. R. (1998). Social influence: Social norms, conformity and compliance. In D. T. Gilbert, S. T. Fiske, \& G. Lindzey (Eds.), The handbook of social psychology (p. 151-192). McGraw-Hill.

[16] Bateson, M., Callow, L., Holmes, J.R., Redmond Roche, M.L. \& Nettle, D. (2013). Do Images of "watching Eyes" Induce Behaviour That Is More pro-Social or More Normative? $A$ Field Experiment on Littering. PLoS ONE, 8, 1-9

[17] Schultz, P.W. (1999). Changing Behavior with Normative Feedback Interventions: A Field Experiment on Curbside Recycling. Basic \& Applied Social Psychology, 21, 25-36.

[18] Ehrlich, C. (2012). Be careful what you wish for but also why you wish for it: Goal-striving reasons and affective subjective well-being. Journal of Positive Psychology, 7, 493-503.

[19] Ehrlich, C. (2018). The development of an extended goalstriving reasons framework: Evidence for its relevance in the workplace, for its theoretical difference to self-concordance and for its buffering effect on work intensity. Journal of Positive Psychology and Wellbeing, 2, 1-23.

[20] Ehrlich, C. (2019). The goal-striving reasons framework: Further evidence for its predictive power for subjective wellbeing on a sub-dimensional level and on an individual goalstriving reasons level as well as evidence for its theoretical difference to self-concordance. Current Psychology, Online First, 1-14.

[21] Ehrlich, C. (2020). Development of the short form of the goalstriving reasons questionnaire. Journal of Well-being Assessment. Online first, 1-22. 
[22] Ehrlich, C. \& Bipp, T. (2016). Goals and subjective wellbeing: Further evidence for goal-striving reasons as an additional level of goal analysis. Personality and Individual Differences, 89, 92-99

[23] Elliot, A. J., \& Thrash, T. M. (2010). Approach and avoidance temperament as basic dimensions of personality. Journal of Personality, 78, 865-906.

[24] Ford, M.E. \& Nichols, C.W. (1987). A taxonomy of human goals and some possible applications. In M. E. Ford \& D. H. Ford (Eds.), Humans as self-constructing systems: Putting the framework to work (pp. 289-311). Hillsdale, NJ: Erlbaum

[25] Ryan, R. M., \& Deci, E. L. (2001). On happiness and human potentials: A review of research on hedonic and eudaimonic well-being. Annual Review of Psychology, 52, 141-166.

[26] Venhoeven L.A., Bolderdijk J.W. \& Steg L. (2016). Why Acting Environmentally-Friendly Feels Good: Exploring the Role of Self-Image. Frontiers in Psychology, 7, 1846.

[27] Joireman, J., Lasane, T., Bennett, J., Richards, D., \& Solaimani, S. (2001). Integrating social value orientation and the consideration of future consequences within the extended norm activation model of pro-environmental behaviour. British Journal of Social Psychology, 40, 133-155.

[28] Schuler, J. (2012). Von der Schwierigkeit des Studiums prosozialen Verhaltens: Weinstein et al. revisited. Master's thesis, University of Mannheim

[29] Jayaratne, M., Mort, G. \& Clare, D'S. (2015). Sustainability Living in a Carbon-Priced Economy: "Shoulds" and "Woulds," Making Amends and Sustainability Guilt. Journal of Nonprofit \& Public Sector Marketing, 27: 3, 285-306

[30] Skinner, B. F. (1938). The Behavior of Organisms: An Experimental Analysis. New York: Appleton-Century

[31] Barr, S., Gilg, A.W. \& Ford, N.J. (2001). A conceptual framework for understanding and analysing attitudes towards household waste-management. Environment and Planning A, 33 (11): 2025-2048

[32] Burgess, J., Harrison, C. M., \& Filius, P. (1998). Environmental communication and the cultural politics of environmental citizenship. Environment and Planning A, 30, 1445-1460.

[33] Defra (2019a). UK Statistics on Waste. Available at: https://www.gov.uk/government/statistics/uk-waste-data (accessed 13 February 2020).

[34] Defra (2019b) Statistics on waste managed by local authorities in England in 2018/19. Available at https://www.gov.uk/government/statistics/local-authoritycollected-waste-management-annual-resultsaccessed $14^{\text {th }}$ February, 2020

[35] HM Treasury (2018). Tackling the plastic problem: using the tax system or charges to address single-use plastic waste. 13 March. Available https://www.gov.uk/government/consultations/tackling-theplastic-problem (accessed 26 September 2018)
[36] Matsueda, N. and Nagase, Y. (2012). An economic analysis of the Packaging waste Recovery Note System in the UK. Resource and Energy Economics, 34, 669-679.

[37] Deci, E. L., \& Ryan, R. M. (2000). The what and why of goal pursuits: Human needs and the self-determination of behaviour. Psychological Inquiry, 11, 227-268.

[38] Judge, T. A., Bono, J.E., Erez, A., \& Locke, E.A. (2005). Core self-evaluations and job and life satisfaction: The role of selfconcordance and goal attainment. Journal of Applied Psychology, 90 (2), 257-268.

[39] Sheldon K. M, Ryan R. M, Deci E. L, \& Kasser T. (2004). The independent effects of goal contents and motives on wellbeing: it's both what you pursue and why you pursue it. Personality \& Social Psychology Bulletin, 30 (4), 475-486.

[40] Sheldon, K. M., \& Elliot, A. J. (1999). Goal striving, need satisfaction, and longitudinal well-being: The selfconcordance model. Journal of Personality and Social Psychology, 76, 482-497.

[41] Sheldon K. M, Elliot A.J., Ryan R.M., Chirkov, V., Kum, Y, Wu, C., Demir, M. \& Sun, Z. (2004). Self-Concordance and Subjective Well-Being in Four Cultures. Journal of CrossCultural Psychology, 35 (2), 209-223.

[42] Sheldon, K. M., \& Houser-Marko, L. (2001). Selfconcordance, goal attainment, and the pursuit of happiness: Can there be an upward spiral? Journal of Personality and Social Psychology, 80 (1), 152-165.

[43] Unsworth, K.L. \& McNeill, I. (2017). Increasing ProEnvironmental Behaviors by Increasing Self-Concordance: Testing an Intervention. Journal of Applied Psychology, 102 (1), 88-103.

[44] Locke, E., \& Latham, G. (2013).Goal setting theory, 1990.In E. Locke \& G. Latham (Eds.), New developments in goal setting and task performance (pp. 3-15). New York: Routledge.

[45] Latkin, C. A., Edwards, C., Davey-Rothwell, M. A., \& Tobin, K. E. (2017). The relationship between social desirability bias and self-reports of health, substance use, and social network factors among urban substance users in Baltimore, Maryland. Addictive behaviors, 73, 133-136

[46] Welsch, H., \& Kühling, J. (2009). Determinants of proenvironmental consumption: The role of reference groups and routine behavior, Ecological Economics, 69, 166-176.

[47] Van Liere, K.D. \& Dunlap, R.E. (1980) The social bases of environmental concern: a review of hypotheses, explanations and empirical evidence. Public Opinion Quarterly, 44, 181197

[48] Deci E. L, Eghrari H., Patrick B.C. \& Leone, D.R. (1994). Facilitating internalization: the self-determination theory perspective. Journal of Personality, 62 (1): 119-42. 